\title{
Cases of community-acquired meticillin-resistant Staphylococcus aureus in an asylum seekers centre in Germany, November 2010
}

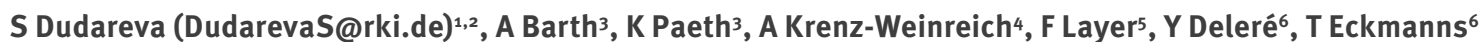

1. European Programme for Intervention Epidemiology Training (EPIET), European Centre for Disease Prevention and Control (ECDC), Stockholm, Sweden

2. Postgraduate Training for Applied Epidemiology, Robert Koch Institute, Berlin, Germany

3. Public Health Department, City of Neumünster, Germany

4. Private practice Dres. Krenz-Weinreich and Schulze, Plön, Germany

5. National Reference Centre for Staphylococci, Robert Koch Institute, Wernigerode, Germany

6. Department for Infectious Disease Epidemiology, Robert Koch Institute, Berlin, Germany

Citation style for this article:

Dudareva S, Barth A, Paeth K, Krenz-Weinreich A, Layer F, Deleré Y, Eckmanns T. Cases of community-acquired meticillin-resistant Staphylococcus aureus in an asylum seekers centre in Germany, November 2010. Euro Surveill. 2011;16(4):pii=19777. Available online: http://www.eurosurveillance.org/ViewArticle. aspx?Articleld $=19777$

In an asylum seeker centre in Schleswig-Holstein, a resident was diagnosed with furuncle caused by a Panton-Valentine leukocidine (PVL)-positive community-acquired meticillin-resistant Staphylococcus aureus (CA-MRSA). As a result of active case finding, 232 of 427 persons (54\% of all residents) were screened for MRSA and two further PVL-positive CA-MRSA cases were identified.

In mid-November 2010, around three weeks after arrival at an asylum seeker centre located in Neumünster, central reception centre of Schleswig-Holstein, Germany, a resident originating from Somalia (case 1) was diagnosed with furuncle caused by a PVL-positive CA-MRSA. On the same day, the resident was moved from a four-bed room to isolation with separate bathroom and toilet.

Following the identification of this case, we decided to perform active case finding and to collect nasal swabs from contacts of case 1 and other residents of the centre. The objectives of the investigation were to identify further cases and to stop possible transmission of PVL-positive CA-MRSA. We were able to reach a high number of residents due to blood collection and a vaccination campaign that were taking place at the same time in the course of a measles outbreak in the centre. In parallel, an intervention plan was developed in order to stop possible transmission. Following the active case finding, four more CA-MRSA cases were identified. Two of these were PVL-positive.

In recent years, emerging community-acquired meticillin-resistant Staphylococcus aureus (CA-MRSA) infections have become a public health problem, and rational strategies for the control of staphylococcal colonisation and infections in non-hospital settings are required [1]. Compared to the general population, close household contacts of the infected person, prison inmates, military recruits and children attending childcare centres are more frequently colonised with CA-MRSA [2-4]. A Swiss study identified non-Swiss/ non European Union citizenship and a history of staying in a collective housing facility as risk factors for CA-MRSA infection [5].

The definition of MRSA as CA-MRSA is primarily based on epidemiological criteria (e.g. acquired outside the hospital setting, lack of risk factors typical for infections with hospital-associated MRSA).Cases of CA-MRSA are frequently positive for the genes encoding the Panton-Valentine leukocidine (PVL), a two-component leukolytic toxin associated with skin and soft-tissue infections, typically furunculosis $[1,4]$. Although the infection is usually confined to skin and soft tissues, systemic complications, including necrotising pneumonia, have been reported [1]. Furthermore, a number of CA-MRSA represent clonal lineages which are different from those of widely disseminated hospital-associated MRSA.

In the asylum seekers centre described here, residents stay from six weeks up to several months, on average two months, before they are placed in other asylum seekers' centres in Schleswig-Holstein. The center consists of former military barracks and the residents are housed in large shared rooms (four to six people) and share a bathroom and on average a toilet per eight rooms. Upon arrival, each resident receives a hygienepackage, containing towel, soap, body lotion, toothbrush and toothpaste. In the central laundry service, everyone can hand over their clothes and towels. Bed linen is centrally washed at $75^{\circ} \mathrm{C}$ with disinfectant. Meals are served in a central dining room. 


\section{Case finding and microbiological investigation}

For our investigation a case was defined as a person residing in the asylum seeker centre during the time of the investigation (between 19 and 22 November 2010) and who was diagnosed with CA-MRSA by laboratory tests. Contacts were defined as persons living in the same bedroom or belonging to the same family and playing together or having close physical contact with the case and residing in the asylum seeker centre during the time of the investigation.

Two days after the initial case was identified, we started convenience sampling and we collected nasal swabs from the contacts of MRSA cases and from the majority of those coming to blood collection and/or vaccination. In addition, for MRSA cases, swabs were taken from the throat, axilla and groin and, where applicable, from wounds. The collected samples were sent for diagnostic tests to a private laboratory in Plön and results were received on a daily basis. Sterile cotton-tipped swabs were used in screening. Plating was on ID-Agar-Plate (BioMérieux, Marcy l'Etoile, France). Suspected colonies were tested by agglutination, thus $S$. aureus was confirmed by Slidex Staph Plus ${ }^{\circledR}$ (BioMérieux, Marcy l'Etoile, France). If the agglutination test was positive, oxacillin resistance was tested by $\mathrm{PBP}_{2}{ }^{\circledR}$ (Oxoid, Basingstoke, Hants, United Kingdom). Samples positive

\section{TABLE 1}

Decolonisation procedures for PVL-positive CA-MRSA cases, asylum seekers centre, Schleswig-Holstein, Germany,

November 2010

\begin{tabular}{|l|c|}
\hline Procedure & Specification \\
\hline - Washing skin and hair with octenidin-based solution & daily \\
\hline - Application of mupirocin nasal ointment & three times daily \\
\hline - Hand disinfection with an alcohol-based antibacterial hand sanitizer & three times daily \\
\hline - Disinfection of personal items (e.g. comb, shaver, glasses, jewellery) with an alcohol-based antimicrobial cleanser & several times daily \\
\hline - Disinfection of bathtub or shower floor and of smooth surfaces with an alcohol-based antimicrobial cleanser & daily \\
\hline - Changing and washing (at least at $60^{\circ} \mathrm{C}$ using a laundry detergent) of towels, bed lines, underwear and clothing & daily \\
\hline - Using new toothbrush & daily \\
\hline
\end{tabular}

CA-MRSA: community-acquired meticillin-resistant Staphylococcus aureus; PVL: Panton-Valentine leukocidine.

\section{TABLE 2}

Cases of CA-MRSA and PVL-positive CA-MRSA cases among asylum seekers, Schleswig-Holstein, Germany, November 2010

\begin{tabular}{|c|c|c|c|c|c|}
\hline \multirow{2}{*}{ Country of origin } & \multirow{2}{*}{ Number of residents } & \multicolumn{2}{|c|}{ Residents tested } & \multirow{2}{*}{$\begin{array}{c}\text { CA-MRSA positive } \\
\text { cases } \\
\text { Number }\end{array}$} & \multirow{2}{*}{$\begin{array}{c}\text { PVL-positive CA-MRSA } \\
\text { cases } \\
\text { Number }\end{array}$} \\
\hline & & Number & $(\%)$ & & \\
\hline Serbia & 74 & 60 & $(81)$ & 3 & 2 \\
\hline The former Yugoslav Republic of Macedonia & 44 & 26 & (59) & 1 & 0 \\
\hline Somalia & 14 & 11 & (79) & 1 & 1 \\
\hline Other & 295 & 135 & $(46)$ & 0 & 0 \\
\hline Total & 427 & 232 & （54） & 5 & 3 \\
\hline
\end{tabular}

CA-MRSA: community-acquired meticillin-resistant Staphylococcus aureus; PVL: Panton-Valentine leukocidine.

\section{TABLE 3}

Demographical information of the PVL-positive CA-MRSA cases and laboratory results, asylum seekers centre, SchleswigHolstein, Germany, November 2010

\begin{tabular}{|c|c|c|c|c|c|c|c|c|}
\hline Case & $\begin{array}{c}\text { Age } \\
\text { (years) }\end{array}$ & $\begin{array}{l}\text { Country of } \\
\text { origin }\end{array}$ & $\begin{array}{l}\text { Days spent in } \\
\text { the centre }\end{array}$ & $\begin{array}{c}\text { Persons sharing } \\
\text { the room }\end{array}$ & $\begin{array}{l}\text { Positive } \\
\text { sites }\end{array}$ & Resistance & $\begin{array}{l}\text { Virulence } \\
\text { factors }\end{array}$ & $\begin{array}{l}\text { SPA type, clonal } \\
\text { complex }\end{array}$ \\
\hline Case 1 & 19 & Somalia & 23 & 4 & $\mathrm{~N}, \mathrm{~T}, \mathrm{Ax}, \mathrm{W}$ & $\mathrm{P}, \mathrm{A}, \mathrm{AS}, \mathrm{Ox}, \mathrm{Ce}, \mathrm{Te}, \mathrm{Co}$ & lukPV+ & to $21, C_{30}$ \\
\hline Case 2 & 4 & Serbia & 41 & 6 & $\mathrm{~N}$ & $\mathrm{P}, \mathrm{A}, \mathrm{AS}, \mathrm{Ox}, \mathrm{Ce}^{\mathrm{b}}$ & lukPV+ etd+ & to 44, CC 80 \\
\hline Case 3 & 8 & Serbia & 41 & 6 & $\mathrm{~N}, \mathrm{~T}$ & $\mathrm{P}, \mathrm{A}, \mathrm{AS}, \mathrm{Ox}, \mathrm{Ce}, \mathrm{Te}, \mathrm{F}$ & lukPV+ etd+ & to 44, CC80 \\
\hline
\end{tabular}

A: amoxicillin; AS: ampicillin/sulbactam; Ax: axilla; Ce: cefaclor; Ci: ciprofloxacin; Cl: clindamycin; Co: co-trimoxazole; CA-MRSA: communityacquired meticillin-resistant Staphylococcus aureus; E: erythromycin; F: fusidic acid; G: gentamicin; L: linezolid; N: nose, Of: ofloxacin; Ox: oxacillin; P: penicillin; PVL: Panton-Valentine leukocidine; R: rifampicin; T: throat; Te: tetracycline; Ti: teicoplanin; V: vancomycin; W: wound.

a Days from arrival in the centre until the day of laboratory confirmation of PVL-positive CA-MRSA.

${ }^{\mathrm{b}}$ The resistance pattern is incomplete ( $\mathrm{F}, \mathrm{L}, \mathrm{V}, \mathrm{Ti}$ were not tested). 
for MRSA were sent to the German National Reference Laboratory for Staphylococci in Wernigerode for further characterisation and typing. A multiplex-PCR for the presence of genes specific for particular CA-MRSAclones was also performed [6]. Nasal swabs were collected again from the three PVL-positive CA-MRSA cases who had undergone decolonisation procedures and were also sent to the private laboratory.

Information on previous hospitalisations, chronic illnesses and previous use of antibiotics was gathered for all MRSA cases.

\section{Intervention for CA-MRSA cases}

In order to control further transmission, persons colonised by PVL-positive CA-MRSA had to follow a stringent decolonisation strategy. The decolonisation protocol used was based on existing national hospital-associated MRSA decolonisation measures [7] and were agreed on in a teleconference with the participation of national MRSA experts and the local health authority. Non-PVL-positive CA-MRSA cases were not entitled for decolonisation at this setting. The measures were implemented upon receipt of the laboratory confirmation for a duration of five days and are summarised in Table 1.

In addition, cases were instructed to enhance hand hygiene and to minimise contact with other residents of the centre during the five days of the decolonisation process. The persons were not allowed to be relocated to other centres prior to successful decolonisation.

To determine the success of decolonisation measures, nasal swabs were taken from these persons three days after the end of the procedure and further swabs shall be applied six days and 12 months after decolonisation. In case of a positive sample three days after the decolonisation process, decolonisation had to be repeated. In case of a positive sample after a second decolonisation process, systemic antibiotics should be applied.

\section{Results \\ At the time of the investigation, 427 residents from 18 nations were in the centre. The median age was 23 years (mean age 22.7, $\mathrm{SD} \pm 14.1$ years) and the male to female ratio was 1.5 . Samples were collected from $54 \%$ of the residents (232/427); five persons were positive for MRSA. Epidemiological criteria and molecular typ- ing results revealed them as CA-MRSA. From those, PVL-positive CA-MRSA were confirmed in three cases. Results on tested persons and laboratory results are presented in Table 2.}

\section{PVL-positive CA-MRSA cases}

Three PVL-positive CA-MRSA cases were identified. Except case 1, no other case had wounds or abscess on the skin and none reported a contact with case 1 . The demographics of the cases and the laboratory results are summarised in Table 3.
A different CA-MRSA strain was identified in each of the three cases. The CA-MRSA strain of case 1 was assigned to $\mathrm{CC}_{30}$, which is prevalent in South East Asia, Oceania, United States of America, United Kingdom, Denmark and the Baltic countries. Sporadic cases are also described in other European countries [8]. Cases 2 and 3 (siblings) belonged to the main European clone ST80, but the resistance pattern differed.

All three cases reported previous hospitalisation in their home countries: case 1 in 2005 for surgery, case 2 in 2009 for conservative treatment, case 3 in 2006 for conservative treatment and in 2008 for surgery. None of the cases reported previous use of antibiotics. Four other family members living in the same room (for cases 2 and 3) and three roommates (for case 1) were swabbed and were negative for MRSA. Eight known play partners for case 2 and 3 were swabbed and were also negative.

\section{Results of the decolonisation}

Nasal swabs were taken from the three treated persons three days after decolonisation. For case 3, the swabs taken three and six days after the first decolonisation were negative, whereas cases 1 and 2 had a negative swab three days after repeated decolonisation. For the case 1 and 2 we do not have the information about the results for the swabs collected after six days. The cases were later transferred to other centres and the respective authorities were informed about the further control tests necessary.

\section{Discussion}

We conducted the investigation and control of cases of CA-MRSA in an asylum seeker centre in Germany. In our investigation, five cases of CA-MRSA were detected. Of those, three were PVL-positive CA-MRSA, however all three were different in respect of the resistance pattern. Furthermore two isolates were assigned to spa-type to 44 (siblings, cases 2 and 3), one isolate presented spa-type to21 (case 1). No transmission in this setting was identified. Regarding the siblings (cases 2 and 3) probably both children were carrying the same CA-MRSA ST80 strain, although the resistance profiles differed in respect of tetracycline and fusidic acid. Genetic studies indicate that the resistance to tetracycline (tetK) and fusidic acid (far 1 ) is located on a 28 $\mathrm{kb}$ plasmid and the loss of this plasmid in case 2 may explain the two different resistance profiles.

Although residents live on average with four more persons per room and an average of 40 persons share the same bathroom and toilet, these factors apparently did not facilitate transmission within the centre. This might be related to the fact that the residents only live in the centre for a relatively short period (on average two months) and that they tend to use personal hygienic items and there are no shared towels in bathrooms and toilets. 
Information about the prevalence of CA-MRSA in nonhospital communities is limited. In healthcare associated Staphylococcus aureus isolates in Europe, the proportion of MRSA varies from below $1 \%$ in Northern Europe to more than $40 \%$ in Malta, Estonia and Portugal [9]. In healthcare associated Staphylococcus aureus isolates in Serbia, the proportion of MRSA is reported as $64 \%$ [10]. No published information about Somalia was found.

Outbreaks of skin infections associated with CA-MRSA within a defined community have been reported previously. Several published outbreaks occurred in children day care centres, sport teams or among military recruits [4]. A furunculous outbreak related to lukS-lukF positive Staphylococcus aureus in a German village has been successfully terminated with stringent decolonisation procedures [11]. However, re-colonisation has been observed within several weeks after successful decolonisation in up to $22 \%$ of cases [12]. Therefore, following up the cases is of great importance.

Although no further transmission was observed, asylum seeker centres are settings where the appearance of PVL-positive CA-MRSA* should be treated with special attention and protocols for decolonisation should be in place. The control strategy described in our report may be helpful for others who have to cope with PVLpositive CA-MRSA* infections in non-hospital settings.

\section{*Authors' correction:}

At the request of the authors, the following change was made on 10 February 2011: 'CA-MRSA' was replaced with 'PVL-positive CA-MRSA' in the last paragraph.

\section{Acknowledgements}

We would like to thank the following persons for their assistance with the investigation:

Dr. Anja Tackla, Petra Stöcker, Susanne Jessen, Dr. Anette Junghans, Dr. Parwis Saedi, Renate Müller, Birgit Richardson, Rita Frahm, Ulf Döhring, Elisabeth Zimmermann, Ralf Krause, Monika Krause. For guidance and advice about intervention strategies we would like to thank Prof.Dr. Martin Mielke, Prof.Dr. Wolfgang Witte, Dr. Anne Marcic, Prof.Dr. Petra Gastmeier. Very special thanks to the EPIET programme, especially to Ioannis Karagiannis. For editorial assistance we would like to thank Edward Velasco.

References

1. Zetola N, Francis JS, Nuermberger EL, Bishai WR. Communityacquired meticillin-resistant Staphylococcus aureus: an emerging threat. Lancet Infect Dis 2005;5(5):275-86.

2. Zafar U, Johnson LB, Hanna M, Riederer K, Sharma M, Fakih MG, et al. Prevalence of nasal colonization among patients with community-associated methicillin-resistant Staphylococcus aureus infection and their household contacts. Infect Control Hosp Epidemiol. 2007;28(8):966-9.

3. Amir NH, Rossney AS, Veale J, O'Connor M, Fitzpatrick F, Humphreys H. Spread of community-acquired meticillinresistant Staphylococcus aureus skin and soft-tissue infection within a family: implications for antibiotic therapy and prevention. J Med Microbiol 2010 Apr;59(Pt 4):489-92.
4. Weber JT. Community-associated methicillin-resistant Staphylococcus aureus. Clin Infect Dis 2005;41 Suppl 4:S269-72.

5. Longtin Y, Sudre P, Francois P, Schrenzel J, Aramburu C, Pastore $R$, et al. Community-associated methicillin-resistant Staphylococcus aureus: risk factors for infection, and longterm follow-up. Clin Microbiol Infect. 2009;15(6):552-9.

6. Strommenger B, Braulke C, Pasemann B, Schmidt C, Witte W. Multiplex PCR for rapid detection of Staphylococcus aureus isolates suspected to represent community-acquired strains. Clin Microbiol. 2008;46(2):582-7.

7. Robert Koch Institute. Staphylokokken-Erkrankungen, insbesondere Infektionen durch MRSA. RKI-Ratgeber Infektionskrankheiten - Merkblätter für Ärzte 2009. [Staphylococcal Infections, particularly MRSA infections. RKI guide for infections - Fact sheet for Doctors 2009]. Berlin:RKI; 7 Sep 2009; Available from: http://www.rki. de/cln_178/nn_504504/DE/Content/Infekt/EpidBull/ Merkblaetter/Ratgeber Mbl Staphylokokken MRSA. html\#doc270992bodyText17

8. Witte W. Community-acquired methicillin-resistant Staphylococcus aureus: what do we need to know? Clin Microbiol Infect. 2009;15 Suppl 7:17-25.

9. European Centre for Disease Prevention and Control (ECDC). Antimicrobial resistance surveillance in Europe 2009. Annual report of the European Antimicrobial Resistance Surveillance Network (EARS-Net). Stockholm: ECDC; 2010. Available from: http://www.ecdc.europa.eu/en/publications/ Publications/1011_SUR_annual_EARS_Net_2009.pdf

10. Suljagic V, Jevtic M, Djordjevic B, Jovelic A. Surgical site infections in a tertiary health care center: prospective cohort study. Surg Today. 2010;40(8):763-71.

11. Wiese-Posselt M, Heuck D, Draeger A, Mielke M, Witte W, Ammon A, et al. Successful Termination of a Furunculosis Outbreak Due to lukS-lukF-Positive Staphylococcus aureus in a German Village by Stringent Decolonisation, 2002 - 2005. Clin Infect Dis. 2007;44(11):e88-95.

12. Mody L, Kauffman CA, McNeil SA, Galecki AT, Bradley SF. Mupirocin-based decolonization of Staphylococcus aureus carriers in residents of 2 long-term care facilities: a randomized, double-blind, placebo-controlled trial. Clin Infect Dis. 2003;37(11):1467-74. 